\title{
Interventional radiofrequency ablation: A promising therapeutic modality in the management of malignant biliary and pancreatic duct obstruction
}

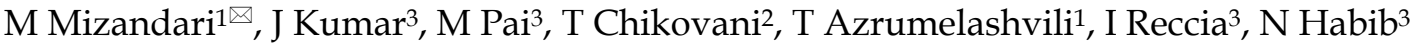 \\ 1. Department of Radiology, Tbilisi State Medical University (TSMU), Tbilisi, Georgia \\ 2. Department of Immunology, Tbilisi State Medical University (TSMU), Tbilisi, Georgia \\ 3. Department of Surgery and Cancer, Imperial College London, London, UK. \\ $\square$ Corresponding author: Prof Malkhaz Mizandari MD, Professor - Department of Radiology of Tbilisi State Medical University (TSMU), Director - University \\ Clinic Department of Diagnostic \& Interventional Radiology, Director - Ultrasound Education Centre "GEOJEFF" 9, Tsinandali st., Tbilisi, 0144, Georgia. \\ Phone/Fax (995 322) 7900 99; email- mgmizandari@gmail.com \\ (c) Ivyspring International Publisher. This is an open access article distributed under the terms of the Creative Commons Attribution (CC BY-NC) license \\ (https://creativecommons.org/licenses/by-nc/4.0/). See http://ivyspring.com/terms for full terms and conditions.
}

Received: 2017.10.11; Accepted: 2017.11.26; Published: 2018.01.05

\begin{abstract}
Background: Malignant biliary and/or pancreatic obstruction has often encountered in the advanced stages of periampullary and cholangicarcinomas. Habib ${ }^{T M}$ Radiofrequency (RF) ablation has been successfully used in the management of various cancers of liver and pancreas. Percutaneous HPB probe (EMcision Ltd, London, UK) is a new addition to this class of tools. It is an endoluminal Radiofrequency (RF) catheter which works on the principle of ablation and induces coagulative necrosis to recanalize the obstructed duct. The aim of this study is to address the technical details of canalization, feasibilities and outcomes of percutaneous endo-luminal Radiofrequency (RF) catheter in patients with unresectable malignancy with obstructed bile and pancreatic duct (PD).

Material and Method: A total of 134 patients with inoperable malignant obstruction of biliary and PD underwent RF based percutaneous endoluminal RF ablation in a tertiary referral centre between December $15^{\text {th }}, 2010$ to August $7^{\text {th }}, 2015$. This device was used in a sequential manner with an intent to recanalize the obstructed. Following the initial catheter drainage of the duct, subsequent percutaneous endobiliary RF ablation, the metallic stent was placed to recanalize the obstructed bile and PD secondary to unresectable malignancy under real-time fluoroscopic guidance.
\end{abstract}

Results: The percutaneous RF based ablation of obstructed bile duct and PD with metallic stent placement was successfully achieved in $130(97.01 \%)$ cases. The three failures were noted in cases of biliary obstruction whilst, one with PD obstruction. The patency restored in 124 and patients, where the procedure was successfully completed and revealed clinical improvement reported.

Conclusion: The percutaneous endoluminal RF based ablation of obstructed duct with metallic stent placement appeared to be a safe, effective procedure and may improve survival in patients with advanced stage cancer presenting with biliary and PD obstruction. Considering the above mentioned evidence, this modality may stand ahead of stenting alone. This could be considered as viable modality in management of such patients where very limited treatment options are available.

Key words: radiofrequency ablation; percutaneous; biliary obstruction; pancreatic duct obstruction; cholangiocarcinoma; pancreatic adenocarcinoma

\section{Introduction}

Malignant biliary obstruction comprises a group of neoplasms that impair bile duct flow and clinically presents with features of obstructive jaundice. Based on site of ductal involvement by the tumour, obstruction can be classified as "distal" or "proximal." Proximal bile duct obstruction is referred to the hilar 
region of bile duct seen in cholangiocarcinomas (i.e., Klatskin tumours), whereas distal bile duct obstruction is commonly encountered as a part of periampullary cancer (1-3). By definition periampullary tumours incorporate a group of neoplasms arising within the two $\mathrm{cms}$ of circumference from the ampulla of Vater, comprising cancer originating from the head of the pancreas, distal bile duct, ampulla of Vater, or second portion of the duodenum $(4,5)$. Nevertheless, PD obstruction is also confronted in association with periampullary carcinoma which may manifest as pancreatitis and/or hyperglycaemia. Decompression of the bile duct and PD with a placement of stent has been practised as the treatment of choice for palliation in patients with malignant biliary and PD obstruction caused by these unresectable neoplasms (6,7). Howbeit, the occlusion of such stents is common owing to tumour in-growth, epithelial hyperplasia, and sludge deposits $(8,9)$. The introductions of newer kind of stents as covered metallic has been made to minimize such complications though success is limited as tumour recurrence depends on the multitude of factors (10). RF ablation has achieved tremendous feet as a curative intent against a liver tumour because of its safety, ease of use, less invasiveness and high level of effectiveness (11) (12). This is a line to the other uses of RF energy where it has been successfully used for various other indications, such as surgical resections and localized ablation of unresectable solid organ tumours through percutaneous, laparoscopic and open surgical approach (13-16).

Habib $^{\mathrm{TM}}$ Percutaneous HPB probe is a novel bipolar endo-luminal RF ablation catheter (EMcision Ltd, London, UK) where the high-frequency alternating current has been utilized to generate thermal energy. The sequential application of probe under real-time fluoroscopic guidance produces an area of coagulative necrosis along the entire length of the malignant obstruction. This RF based probe has been developed in our lab and practised with intent to increase the duration of stent patency while exerting local tumour destruction prior to stent placement $(17-20)$. We have reported its successful use in the palliative management of patients with malignant biliary or PD obstruction due to the inoperable bile duct and pancreatic head adenocarcinomas through endoscopic and percutaneous approach (21).

Pancreatic duct (PD) obstruction is commonly encountered with neoplasms of the pancreatic head, duodenum and ampulla of Vater. Only $10-20 \%$ of pancreatic carcinoma is amenable to definitive curative surgery at initial presentation (22-24). There is a growing interest of $\mathrm{RF}$ ablation in various lesions of the pancreas, including unresectable pancreatic carcinoma as RF ablation is feasible with acceptable mortality and increased survival (25-30). On the same note, our group has recently reported the use of endoscopic ultrasound (EUS) guided RF ablation in patients with advanced pancreatic cancers with encouraging results (31).

The purpose of this pilot study is to outline the outcomes and feasibilities of the application of endoluminal RF ablation catheter in recanalization of the obstructed bile and/or PD in patients with unresectable malignancy prior to placement of the metallic stent.

\section{Material and Methods}

Study Design: We prospectively enrolled patients presenting with features of biliary and PD obstruction secondary to periampullary carcinoma and cholangiocarcinoma at our tertiary centre "High Technology Medical Centre-University Clinic" between December 15 $5^{\text {th }}, 2010$ to August 7th 2015 . This trial was registered and approved by the Institutional Review Board of the Tbilisi State Medical University. Informed written consent was obtained from each recruited patient. The primary endpoint of the study was the technical success in terms of endobiliary and PD recanalization following endoluminal RF ablation of the tumour obstructing the duct through stent deployment. The secondary endpoints were post procedure clinical improvement regarding cholestatic symptoms, laboratory data, fever, pain, nausea, improved well-being and mortality.

Subjects: This prospective study was conducted from December 15 $5^{\text {th }}, 2010$ till August $7^{\text {th }}, 2015$. A total of 154 procedures were performed in 134 patients presented with features of biliary and PD obstruction secondary to neoplasm liver hilum, bile duct and periampullary cancers, which were deemed inoperable because of vascular invasion and/or distant metastasis. All patients were investigated with blood tests, ultrasound, computer tomography (CT) and magnetic resonance imaging (MRI) in order to establish the clinical diagnosis. The patients with bile duct or PD obstruction underwent palliative therapy, including percutaneous drainage followed by recanalization procedure using endo-luminal RF ablation and stenting. The initial ten patients with biliary obstruction underwent balloon ductoplasty following RF based recanalization alone while in the remaining 117 patients procedure was completed with self-expanding metal stent (SEMS) placement. The duct patency restoration procedures were performed one to three weeks following the drainage, using the drainage fistula. 


\section{Procedure and Complication}

\section{Endobiliary RF ablation of malignant bile duct obstruction}

The percutaneous endobiliary interventions were performed in 127 patients at a tertiary referral centre by a interventional radiologist (MM) under moderate sedation using midazolam, diprivan and local anaesthesia. The details of this minimally invasive technique i.e. percutaneous endobiliary $\mathrm{RF}$ ablation procedure, safety and feasibility of the technique, has been outlined below. Further details can be seen in our previously published article (21). The Habib ${ }^{\mathrm{TM}}$ Percutaneous HPB probe (EMcision Ltd, London, UK) is a single-use, disposable, bipolar 8 French (Fr) catheter with a working length of $90 \mathrm{~cm}$, which has been approved by US Food and Drug Administration $510(\mathrm{k})$ and the European Union certificate of Conformity for marketing clearance.

The mandatory percutaneous transhepatic biliary drainage (PTBD) was successfully achieved in all patients. The first step of biliary recanalization required the positioning of the appropriate diameter introducer sheath into the drainage track over the guidewire with wire manipulation by 5 Fr guiding catheter across a tumour obstructed segment of the bile duct. The contrast was injected through the introducer sheath following which catheter was guided and manipulated across the stricture. This was done to detect the stricture length and to evaluate the possibility of papilla preservation during the stent placement (Figure 1,2) The endoluminal RF ablation catheter was then inserted over guide wire via introducer sheath (Figure 3). The endo-luminal RF ablation catheter was coupled to a radiofrequency generator (RF 1500X, RITA Medical Systems Inc, Fremont, CA; or ERBE VIO200D, ERBE Medical UK Ltd, Leeds, UK) to deliver 15 Watts over a duration of 2-min for each application. The RF energy was applied in a sequential manner along the entire length of the malignant stricture under fluoroscopic guidance. The procedure was followed by balloon ductoplasty in the first 10 cases whilst, self-expanding metallic stents (SEMS) placed with or without preand post-dilation in the rest cases (Figure 4). The dilatation was achieved by 8 to $10 \mathrm{~mm}$ balloon as required. We would like mention here that decision regarding the change in technique, i.e., placement of stent following balloon dilatation was made in view that RF ablation alone in tumour tissue during recanalization causes swelling. This causes further narrowing in a tract which was not effectively channelled with balloon dilatation. In order to ensure the complete patency in ablated duct segment, a decision regarding placement of metallic stent has been made. Thus in remaining 114 patients we have also placed metallic stent following the ablation with or without balloon dilatation.

A total of 144 attempts were made to recanalize the obstructed bile duct in 127 patients with unresectable malignant tumours. The most common causes of obstructions were cholangiocarcinoma in 46 patients, followed by pancreatic cancer in 32 and liver invasion was seen in 26 cases. Apart from that gallbladder cancer was noted in 8 cases, hepatocellular carcinoma in seven and tumour of the ampulla of Vater in eight.

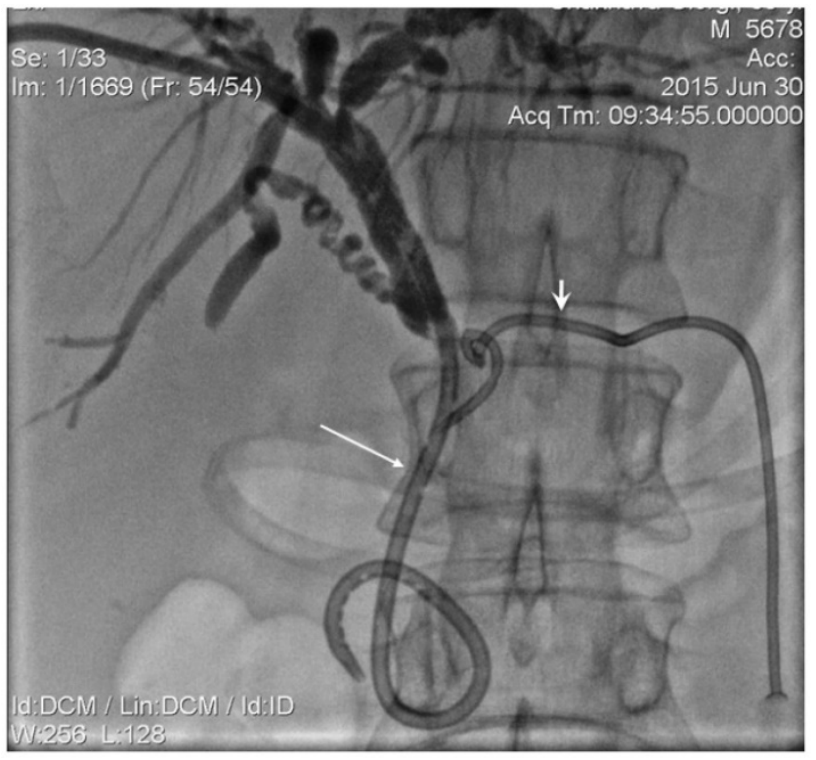

Figure 1. Inoperable pancreatic head cancer presented with jaundice and PD dilation. Biliary external-internal (long arrow) and PD drainage (short arrow) performed.

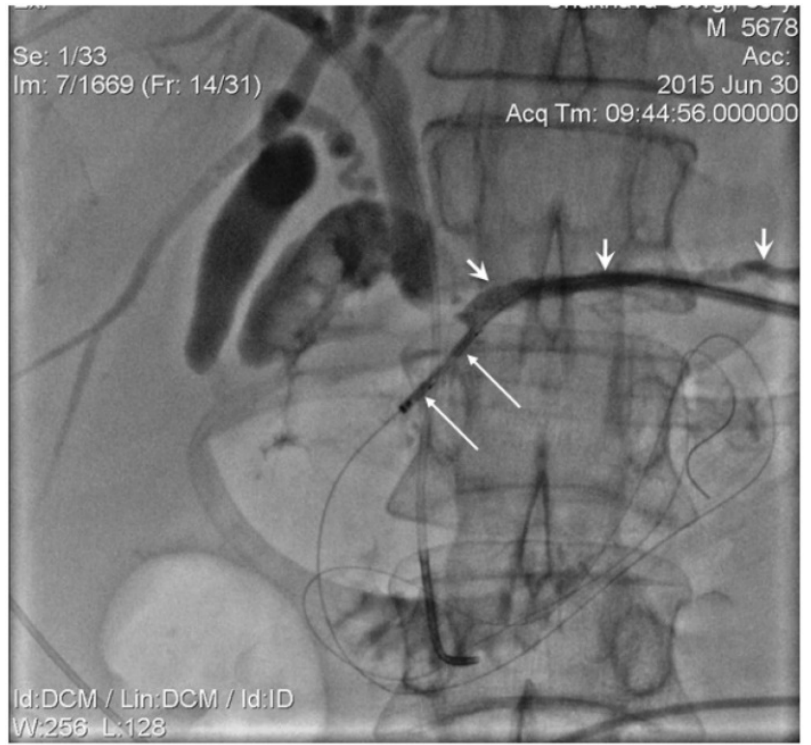

Figure 2. Contrast injected into PD (short arrows) via introducer sheath. PD blocked segment was processed by $5 \mathrm{Fr}$ diameter endo-luminal RF electrode, adequately positioned over the wire (long arrows identify RF device electrodes). 


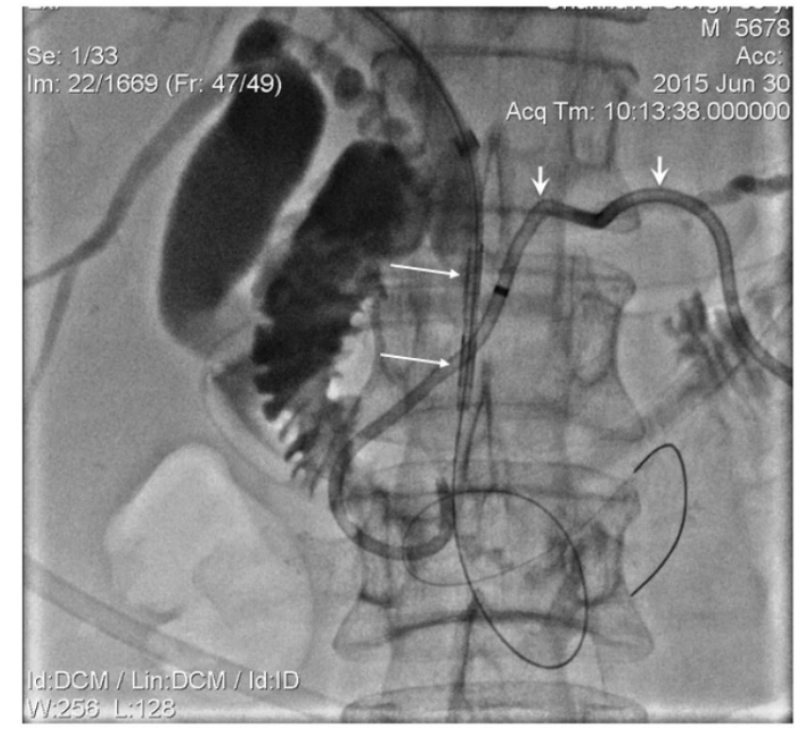

Figure 3. Endoluminal $8 \mathrm{Fr}$ diameter RF catherter (long arrows) was positioned in biliary duct obstructed segment over the wire. External-internal PD drain was identified by short arrows.

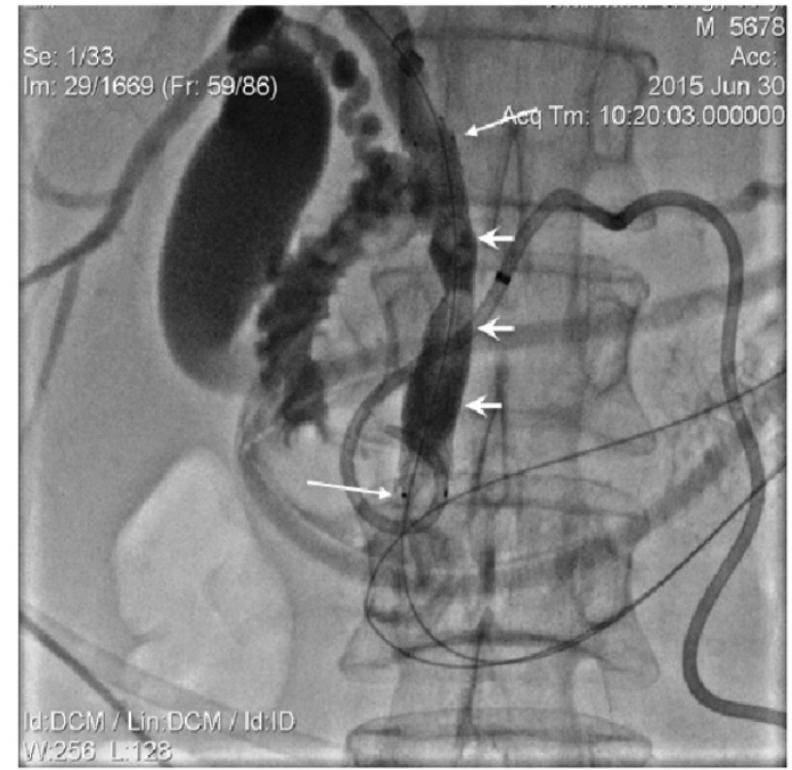

Figure 4. $10 \mathrm{~mm}$ diameter SEMS (long arrows) positioned in CBD. Strictured segment post-dilatation was performed by balloon (short arrows).

Pancreatic Intraductal RF ablation in malignant pancreatic duct (PD) obstruction

The procedure for ablation of tumours obstructing PD was similar to biliary intervention. The percutaneous PD drainage performed in the first instance under the guidance of either combined ultrasound-fluoroscopy or CT-fluoroscopy. Once the patient's general well-being had improved following the percutaneous drainage; Later the endoluminal RF ablation and metallic stent placement were placed under fluoroscopy guidance using the PD drainage track. The first step of the procedure involved the insertion of the introducer sheath over the guidewire and manipulation of the wire across the obstructed segment of PD using 4 or 5 Fr guiding or advantage catheter. The feasibility of papilla preservation was evaluated following the injection of contrast through the introducer sheath and the guiding or advancement of a catheter during the stent placement (Figure 5). A 5Fr endoluminal RF ablation catheter inserted over the guidewire and positioned across a tumour obstructed segment in the PD under fluoroscopic guidance (Figure 2). The RF energy of 15 Watts was applied over 2 minutes in a sequential manner along the entire length of the malignant stricture under fluoroscopic guidance, and 5 or $6 \mathrm{~mm}$ balloon mounted or SEMS was placed in succession (Figure 6). The decision regarding the number of RF applications ( 1 or 2$)$ and the length of a stent $(4 \mathrm{~cm}$ or $6 \mathrm{~cm})$ was tailored according to the length of the stricture.

A total of seven patients with malignant PD obstruction due to inoperable advanced adenocarcinoma of the pancreatic head with recently manifested pancreatitis and/or hyperglycaemia underwent PD segment recanalization (Figure 7). In six of them, PD recanalization was attempted before, after or simultaneous with biliary recanalization by using endoluminal RF ablation catheter and stenting. In the remaining case, PD intervention was performed in a patient who had bilio-enteric anastomosis while, attempted Whipple's procedure.

\section{Results}

In the present study, intraductal RF ablation using endoluminal RF ablation catheter has been successfully completed in $130(97.01 \%)$ out of 133 patients. The procedures were well tolerated in all the patients. In 4 cases (3.6 \%) the procedure could not be performed because of wire conduction failure encountered in three instances with biliary obstruction whilst, one case with main pancreatic duct obstruction.

\section{Endobiliary RF ablation for malignant bile duct obstruction}

The characteristics of patients who underwent biliary RF ablation procedures was outlined in Table 1. Here 124 out of 127 patients with inoperable malignant biliary obstruction, successfully underwent percutaneous endobiliary RF ablation using endoluminal RF ablation catheter followed by balloon ductoplasty or SEMS insertion. A total of 144 percutaneous endobiliary RF ablation procedures were attempted over the period of study. The RF ablation of malignant biliary strictures was done 
following external biliary decompression with an external or internal-external biliary drainage. Due to the lobar or segmental level of the malignant biliary obstruction, RF ablations was done twice in 16 patients while thrice in two patients. In 10 cases ductoplasty by balloon dilatation had been done whilst rest 114 cases SEMS placed across the malignant stricture segment. The percutaneous biliary drain was removed following a satisfactory cholangiogram.

Table 1. Characteristics of patients undergoing bile duct interventions through Endobiliary RFA

\begin{tabular}{|c|c|c|c|c|}
\hline \multicolumn{4}{|c|}{ Total number of patients } & 127 \\
\hline \multicolumn{4}{|c|}{ Age (median), yr } & $\begin{array}{l}62.5 \\
(33-92)\end{array}$ \\
\hline \multicolumn{4}{|c|}{ Male / Female ratio } & $69 / 58$ \\
\hline \multirow[t]{26}{*}{ Diagnosis } & \multirow[t]{6}{*}{ Cholangiocarcinoma } & \multirow{6}{*}{$\begin{array}{l}\text { Bismuth } \\
\text { type }\end{array}$} & & 46 \\
\hline & & & I & 26 \\
\hline & & & II & 16 \\
\hline & & & IIIA & 1 \\
\hline & & & IIIB & 1 \\
\hline & & & IV & 2 \\
\hline & $\begin{array}{l}\text { Pancreatic } \\
\text { adenocarcinoma }\end{array}$ & & & 32 \\
\hline & \multirow[t]{6}{*}{ Liver metastatic invasion } & \multirow{6}{*}{$\begin{array}{l}\text { Bismuth } \\
\text { type }\end{array}$} & & 26 \\
\hline & & & I & 25 \\
\hline & & & II & 0 \\
\hline & & & IIIA & 1 \\
\hline & & & IIIB & 0 \\
\hline & & & IV & 0 \\
\hline & \multirow[t]{6}{*}{ Hepatocellular carcinoma } & \multirow{6}{*}{$\begin{array}{l}\text { Bismuth } \\
\text { type }\end{array}$} & & 7 \\
\hline & & & I & 7 \\
\hline & & & II & 0 \\
\hline & & & IIIA & 0 \\
\hline & & & IIIB & 0 \\
\hline & & & IV & 0 \\
\hline & $\begin{array}{l}\text { Ampullary } \\
\text { adenocarcinoma }\end{array}$ & & & 8 \\
\hline & \multirow[t]{6}{*}{ Gallbladder carcinoma } & \multirow{6}{*}{$\begin{array}{l}\text { Bismuth } \\
\text { type }\end{array}$} & & 8 \\
\hline & & & $\mathrm{I}$ & 7 \\
\hline & & & II & 1 \\
\hline & & & IIIA & 0 \\
\hline & & & IIIB & 0 \\
\hline & & & IV & 0 \\
\hline
\end{tabular}

In two (1.6\%) patients, contrast extravasation following the RF ablation was detected and managed conservatively by stent placement and antibiotics. Besides that, there were no observed technique specific complications, such as haemorrhage, vessel injury, visceral injury or infection. The biliary patency restored in all of the 124 patients, where the procedure was successfully completed and revealed clinical improvement in the successive days. The stricture length varied from 1.5 to $4.5 \mathrm{~cm}$. The duration of biliary stent patency varied from 3 weeks to 14 months. The overall patient survival ranged from 3 weeks to 47 months (Table 2).

\section{Pancreatic Intraductal RF ablation in malignant pancreatic duct (PD) obstruction}

The characteristics of patients who underwent PD, RF ablation using endo-luminal RF ablation catheter has been shown in Table 3. The Percutaneous PD drainage with metallic stent placement was successfully performed in $6(85.7 \%)$ out of 7 patients of locally advanced adenocarcinoma of the pancreatic head. In one case the procedure could not be performed due to the guidewire conduction failure through obstructed PD segment. The procedure was well tolerated in all the patients, and no procedure-related complications were observed. The stricture length varied from 1.5 to $3.0 \mathrm{~cm}$, and post-procedure duct diameter was 5 or $6 \mathrm{~mm}$ depending on the implanted stent parameters. In all the cases, improvement in clinical status, well-being and normalization of biochemical markers of pancreatitis has been observed following the PD drainage. Two patients with uncontrolled diabetes had achieved significant improvement in the blood sugar control.

In five $(83.3 \%)$ of the six completed cases, the life-long patency of the implanted stent has been observed while in one $(16.7 \%)$ case the stent blockage noted due to tumour overgrowth during the follow-up of 11 months. The overall survival ranged from 3 to 18 months (Table 4).

Table 2. Characteristics of Endobiliary RFA recanalization procedure in the bile duct

\begin{tabular}{|l|l|}
\hline Length of stricture $(\mathrm{cm})^{\text {a }}$ & $(3.125 \pm 1.125)$ 1.5-4.5 \\
\hline RFA device diameter & $8 \mathrm{Fr}$ \\
\hline \multirow{2}{*}{ No. of ablations } & $\mathrm{I}(113)$ \\
\cline { 2 - 3 } & $\begin{array}{l}\text { II (14) } \\
\text { III (2) }\end{array}$ \\
\hline Duration of ablation $(\mathrm{min})$ & 2 \\
\hline Ablation energy (watts) & $10-15$ \\
\hline Pre-ablation diameter $(\mathrm{mm})$ & $0-2$ \\
\hline Post-ablation diameter $(\mathrm{mm})$ & $8-10$ \\
\hline Technical success rate & $97.6 \%$ \\
\hline
\end{tabular}

a Mean \pm standard deviation rest of the parameters are median (range)

Table 3. Characteristics of patients undergoing pancreatic duct interventions through Endobiliary RFA

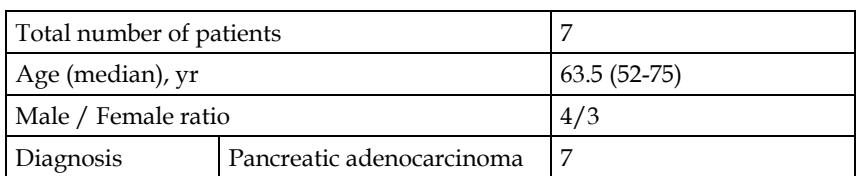


Table 4. Characteristics of Endobiliary RFA recanalization procedure in the pancreatic duct

\begin{tabular}{|l|l|}
\hline Length of stricture $(\mathrm{cm})^{a}$ & $2.21 \pm 1.075$ \\
\hline RFA device diameter & $5 \mathrm{Fr}$ \\
\hline \multirow{2}{*}{ No. of ablations } & $\mathrm{I}(4)$ \\
\cline { 2 - 2 } & $\mathrm{II}(2)$ \\
\hline Duration of ablation $(\mathrm{min})$ & 2 \\
\hline Ablation energy (watts) & $10-15$ \\
\hline Preablation diameter $(\mathrm{mm})$ & 0 \\
\hline Postablation diameter $(\mathrm{mm})$ & $5-6$ \\
\hline Technical success rate & $85.7 \%$ \\
\hline
\end{tabular}

${ }^{a}$ Mean \pm standard deviation rest of the parameters are median (range)

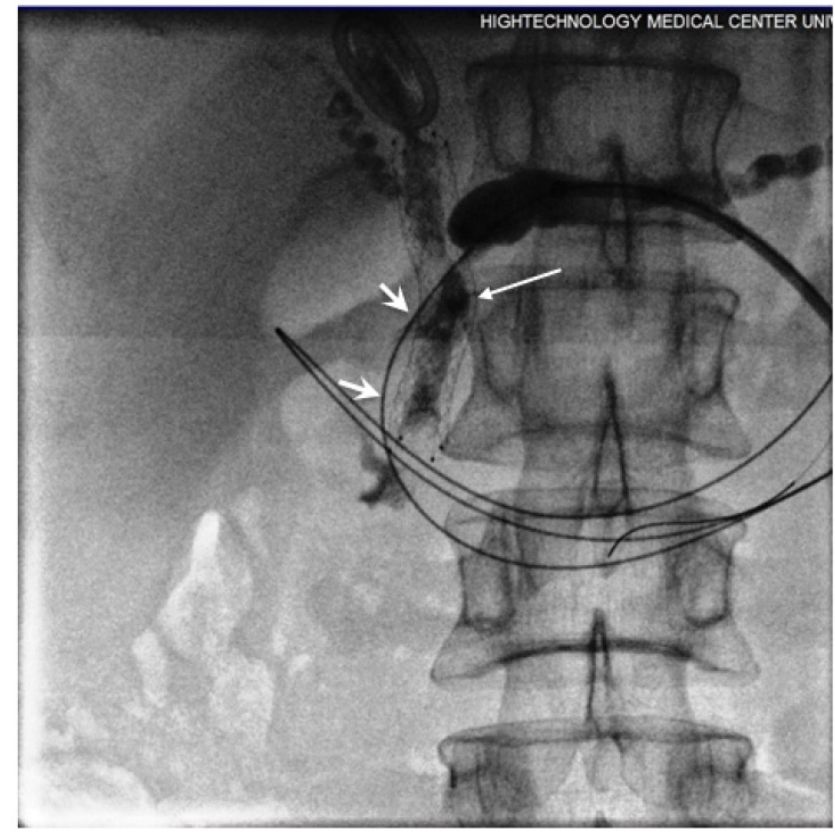

Figure 5. Contrast injected via introducer sheath showed obstruction in PD secondary to dense tumour and post-ablation tissue swelling. The guide wire conducted into the duodenum through the obstructed segment (short arrows). Free passage of contrast was seen following the stent placement (long arrows).

\section{Discussion}

The RF-based device has been evolved as a safe and effective modality for resection and ablation of various tumours over the years. It has been successfully utilized in the management of the cancers of liver, pancreas and spleen through the ablation of focal malignant diseases (32-34). During RF ablation, the energy passes between the electrodes and biological tissues to cause coagulation of a selected area resulting in rapid movement of intracellular ions in opposite directions. Ionic motion creates frictional forces that generate heat around the electrodes and eventually, around the tissue surrounding the catheter. Thus, the RF generated heat produced an area of coagulative necrosis to the target tissue with a curative or palliative intent, which can be monitored by real-time ultrasonography or computed tomography (35-39).
Along with that, RF ablation is a strong adjuvant for antitumor response as it induces an immunomodulatory response targeting the tumour antigens. The recent advancement in immunological concepts has put RF technique ahead of other devices. Which needs worth mentioning here as they As RFablated margins attract CD8 $\mathrm{T}$ cells and macrophages which phagocytose the debris and tumour cells at the coagulated margin, thus aids an early recovery and minimizes postoperative complications (40-44).

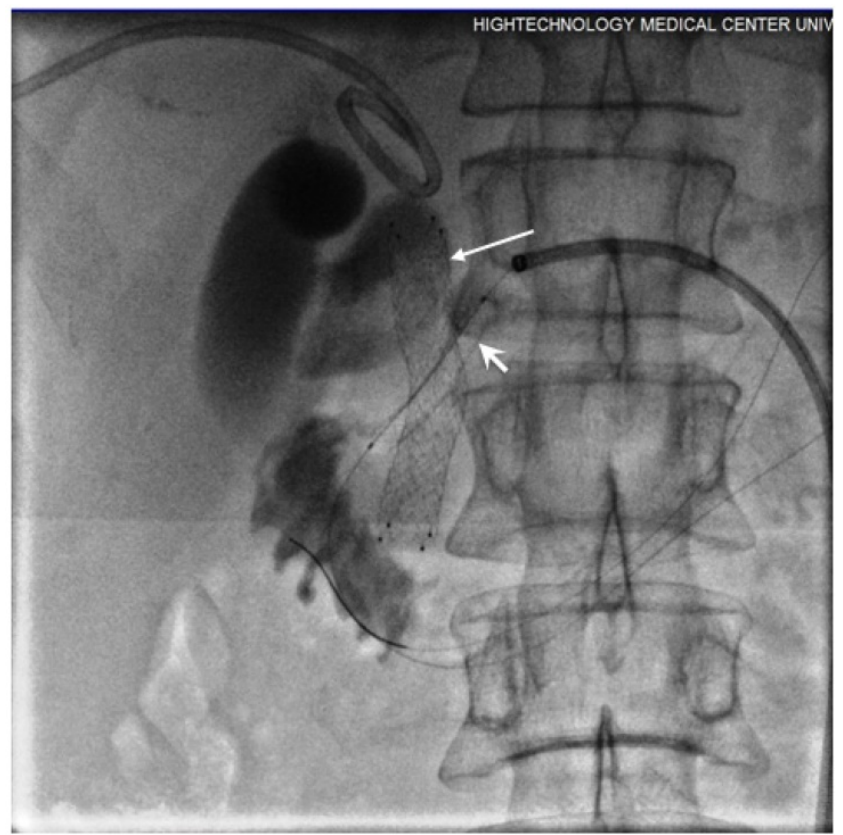

Figure 6. The balloon mounted PD stent (short arrow) released following the inflation of balloon whilst long arrow identifies the biliary stent.

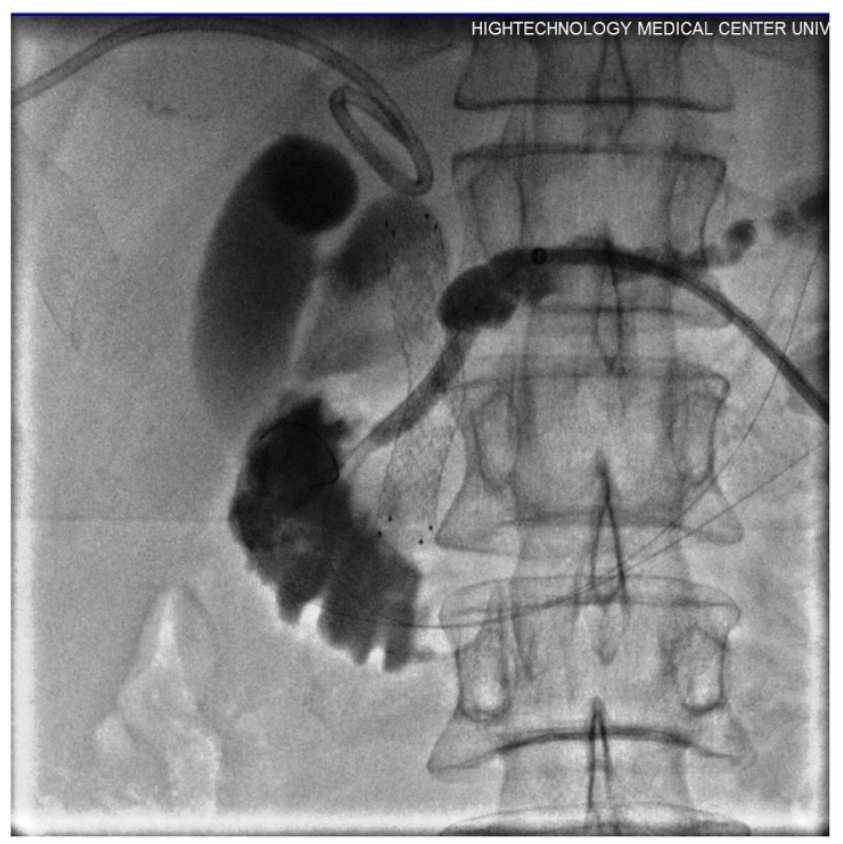

Figure 7. The patency of PD completely restored as shown following final contrast injection via introducer sheath. 
The majority of common bile duct (CBD) obstruction seen in advanced tumours of bile duct and pancreas whilst, in $80 \%$ of the cases, these tumours are unresectable at the time of presentation (45-47). Considering the extent and the severity of obstructive symptoms the palliative therapy in the form of decompression is the only justified available treatment option. The palliative biliary decompression following metallic stent placement has achieved better outcomes in terms of lower complication rate than surgery (48-50). In spite, of these benefits, the reported reocclusion rate is up to 50 $\%$ in the first $6-8$ months following the primary stenting (51-53). The stent reocclusion is frequently reported because of tumour in-growth, epithelial hyperplasia and sludge deposits. The RF ablation has not only accomplished tremendous feet in the management of malignancies of liver since its introduction in the early 1990s but also showed a survival benefit by inhibiting tumour recurrence at the resection margin (54-57). The contemporaneous success of endoluminal RF ablation has also been translated into obstructing diseases of the colon and oesophagus (58-60). More recently, this technique has been recognized for its potential in the palliative management of malignant biliary strictures (61-63).

The main rationale behind this approach is that intraductal RF ablation through endoluminal RF ablation catheter may prolong the stent patency by destroying tumour volume and achieving local tumour control through its immunomodulatory effect. In addition, it helps in the palliation of the large tumours in conjunction with chemotherapy. Thus, delivering the RF energy "inside" the biliary system, produces a thermal effect that recanalizes the malignant biliary obstruction though coagulation while immunomodulatory effect put control on tumour regrowth. Henceforth, this causes a potential delay in tumour growth through the immunomodulatory effect, thus helping in prolongation of the duration of stent patency (21). The Habib $^{\mathrm{TM}}$ Endo HPB probe works on the same principle and has been successfully deployed via an endoscopic route in a pilot study of 22 patients. It has demonstrated safety equivalence as par with the other minimally invasive procedure and achieved excellent 90-day stent patency following the palliation for malignant obstructive jaundice (18).

Kahaleh et al., 2013 did a pilot study to analyze the feasibility and early results of endoluminal RF based ablation in patients with malignant biliary strictures. In addition to the justification of ease and safety, they also reported a significant increase in the recanalized diameter of malignant biliary obstruction following endoluminal RF ablation (64). In 2014 Pai et al., compared the results of endobiliary RF ablation and metal stenting with the outcomes of palliative metal stenting alone. The patients were matched in terms of age, diagnosis, performance status, and palliative chemotherapy in both groups. Apart from, the safety and feasibility of the percutaneous intrabiliary tract RF ablation in malignant obstruction of bile duct, it had been assessed to clear the occluded metal stents in patients with unresectable malignant biliary strictures (65). The endobiliary RF ablation appeared to improve the survival in patients with an end-stage tumour induced mechanical jaundice. Thus, in a disease with limited treatment options, this modality may prove to be beneficial compared to the stenting alone (66).

The therapeutic practice of using RF energy is not new for the cases of pancreatic adenocarcinoma $(67,68)$. Various studies have reported the use of RF devices to ablate (without resection) unresectable locally advanced PDAC with significant median survival benefit ranging from 20-33 months (69) (31). The reported 30 days morbidity and mortality were in a range of $10-43 \%$ and $0-19 \%$ respectively (70-72). The adverse events following pancreatic parenchymal RF ablation are associated with the duration of $\mathrm{RF}$ ablation as the pancreas is very thermo-sensitive organ [9]. Pai et al., 2015 reported the application of RF ablation via the novel Habib EUS-RFA catheter (Emcision Ltd, UK) in cystic pancreatic neoplasms and NET as feasible and safe therapeutic option (30). The use of low energy and non-sequential application for the ablation has lowered the morbidity despite the theoretical possibility massive necrosis of pancreas following RF ablation might occur due to close proximity sequential ablations in the same session. This risk can be well minimized in experience hands and proper post-procedural follow-up (11) (73).

The presence of percutaneous drain makes the endoluminal RF ablation of obstructed PD, a safe and feasible treatment option as it offers the palliation, against the pancreatic exocrine insufficiency, hyperglycaemia and recurrent pancreatitis by relieving the pancreatic duct obstruction. The RF ablation helps to maintain the implanted stent patency by preventing or postponing the tumour ingrowth/overgrowth due to its immunomodulatory effect. The present study has certain limitations, as non-randomized design, unintended biases of patient selection which might influence the analysis. In spite of these limitations, the study showed the feasibility and applicability of percutaneous endoluminal RF ablation catheter as a safe and effective modality for palliation in patients of advanced unresectable cancers of the bile duct and pancreas presenting with obstructive symptoms. 
Nevertheless, further randomized studies are warranted to determine the safety, efficacy, long-term stent patency and patient survival following the use of endoluminal RF ablation catheter.

\section{Conclusions}

The percutaneous endoluminal RF ablation catheter appears to be a safe and effective modality for the palliative management of inoperable biliary and pancreatic duct cancers presenting with obstructive symptoms. The energy is delivered "inside" the bile or pancreatic ductal system, through the endoluminal RF ablation catheter takes advantage of the thermal effect RF as a means to locally destroy the malignant stricture. Along with that localized coagulative necrosis and immunomodulatory effect of RF ablation delays tumour re-growth and may extend the duration of stent patency. Henceforth, the placement of a metallic stent in obstructed bile and pancreatic duct following the endoluminal RF ablation appears as the optimum way to maintain the duct patency.

\section{Ethical approval}

All procedures performed in studies involving human participants were in accordance with the ethical standards of the institutional and/or national research committee and with the 1964 Helsinki declaration and its later amendments or comparable ethical standards.

\section{Conflict of Interest}

Nagy Habib has a share in company Emcision limited that developed Endo HPB Probe apart from that none of the contributing authors have any conflict of interest, including specific financial interests or relationships and affiliations relevant to the subject matter or materials discussed in the manuscript.

\section{References}

1. Bennett JJ, Green RH. Malignant Masquerade: Dilemmas in Diagnosing Biliary Obstruction. Vol 18, Surgical Oncology Clinics of North America. 2009: 207-14.

2. Boulay BR, Gardner TB, Gordon SR. Occlusion rate and complications of plastic biliary stent placement in patients undergoing neoadjuvant chemoradiotherapy for pancreatic cancer with malignant biliary obstruction. J Clin Gastroenterol. 2010;44(6):452-5

3. Boulay BR, Parepally M. Managing malignant biliary obstruction in pancreas cancer: Choosing the appropriate strategy. World J Gastroenterol. 2014;20(28):9345-53.

4. Safaie-Shirazi S, Zike WL, Condon RE. Periampullary carcinoma. J Surg Oncol. 1973;5(1):71-5

5. Kairaluoma MI, Partio E, Stahlberg M, Laitinen S. Pancreatic and periampullary carcinoma. Ann Chir Gynaecol. 1984;73(4):199-205.

6. Van Dijkum EJMN, Kuhlmann KFD, Terwee CB, Obertop H, De Haes JCJM, Gouma DJ. Quality of life after curative or palliative surgical treatment of pancreatic and periampullary carcinoma. Br J Surg. 2005;92(4):471-7.

7. Lillemoe KD, Sauter PK, Pitt HA, Yeo CJ, Cameron JL. Current status of surgical palliation of periampullary carcinoma. Surg Gynecol Obs. 1993;176(1):1-10

8. Wu Y, Tang Z, Fang H, Gao S, Chen J, Wang Y, et al. High operative risk of cool-tip radiofrequency ablation for unresectable pancreatic head cancer 1 . J Surg Oncol. 2006;94(5):392-5
9. Matsui Y, Nakagawa A, Kamiyama Y, Yamamoto K, Kubo N, Nakase Y. Selective thermocoagulation of unresectable pancreatic cancers by using radiofrequency capacitive heating. Pancreas [Internet]. 2000;20(1):14-20. Available from: http://www.ncbi.nlm.nih.gov/pubmed/10630378

10. Krokidis M, Orgera G, Fanelli F, Hatzidakis A. Covered biliary metal stents: which, where, when? Gastrointest Endosc [Internet]. Elsevier; 2017 Jun 15;74(5):1173-4. Available from: http://dx.doi.org/10.1016/j.gie.2011.07.002

11. Elias D, Baton O, Sideris L, Lasser P, Pocard M. Necrotizing pancreatitis after radiofrequency destruction of pancreatic tumours. Eur J Surg Oncol. 2004;30(1):85-7.

12. Quesada R, Burdío F, Iglesias M, Dorcaratto D, Cáceres M, Andaluz A, et al. Radiofrequency Pancreatic Ablation and Section of the Main Pancreatic Duct Does Not Lead to Necrotizing Pancreatitis. Pancreas. 2014;43(6):1-7.

13. Carrafiello G, Laganà D, Mangini M, Fontana F, Dionigi G, Boni L, et al Microwave tumors ablation: Principles, clinical applications and review of preliminary experiences. Int J Surg. 2008;6(SUPPL 1).

14. Tatli S, Tapan U, Morrison PR, Silverman SG. Radiofrequency ablation: Technique and clinical applications. Diagnostic Interv Radiol [Internet]. 2012;18:508-16.

15. McDermott S, Gervais DA. Radiofrequency ablation of liver tumors. Semin Intervent Radiol. 2013;30(1):49-55.

16. Lencioni R, Crocetti L. Radiofrequency Ablation of Liver Cancer. Tech Vasc Interv Radiol. 2007;10(1):38-46.

17. Gervais DA, Goldberg SN, Brown DB, Soulen MC, Millward SF, Rajan DK. Society of Interventional Radiology position statement on percutaneous radiofrequency ablation for the treatment of liver tumors. J Vasc Interv Radiol [Internet]. 2009;20(7 Suppl):S342-7.

18. Steel AW, Postgate AJ, Khorsandi S, Nicholls J, Jiao L, Vlavianos P, et al. Endoscopically applied radiofrequency ablation appears to be safe in the treatment of malignant biliary obstruction. Gastrointest Endosc. 2011;73(1):149-53.

19. Wu TT, Li HC, Li WM, Ao GK, Lin H, Zheng F, et al. Percutaneous Intraluminal Radiofrequency Ablation for Malignant Extrahepatic Biliary Obstruction: A Safe and Feasible Method. Dig Dis Sci. 2015;60(7):2158-63.

20. Krokidis M, Hatzidakis A. Percutaneous minimally invasive treatment of malignant biliary strictures: Current status. Vol. 37, CardioVascular and Interventional Radiology. 2014. p. 316-23.

21. Mizandari M, Pai M, Xi F, Valek V, Tomas A, Quaretti P et al Percutaneous intraductal radiofrequency ablation is a safe treatment for malignant biliary obstruction: feasibility and early results. Cardiovasc Intervent Radiol. United States; 2013 Jun;36(3):814-9.

22. Bardeesy N, DePinho R a. Pancreatic cancer biology and genetics. Nat Rev Cancer. 2002;2(12):897-909.

23. Ghaneh P, Costello E, Neoptolemos JP. Biology and management of pancreatic cancer. Postgrad Med J. 2008;84(995):478-97.

24. Makohon-Moore A, Iacobuzio-Donahue CA. Pancreatic cancer biology and genetics from an evolutionary perspective. Nat Rev Cancer [Internet]. 2016;16(9):553-65.

25. Carrara S, Arcidiacono PG, Albarello L, Addis A, Enderle MD, Boemo C, et al. Endoscopic ultrasound-guided application of a new hybrid cryotherm probe in porcine pancreas: A preliminary study. Endoscopy. 2008;40(4):321-6.

26. Ierardi AM, Lucchina N, Petrillo M, Floridi C, Piacentino F, Bacuzzi A, et al. Systematic review of minimally invasive ablation treatment for locally advanced pancreatic cancer. Radiol Med [Internet]. 2014;483-98.

27. Seicean A, Tefas C, Ungureanu B, Săftoiu A. Endoscopic ultrasound guided radiofrequency ablation in pancreas. Vol. 61, Hepato-Gastroenterology. 2014. p. 1717-21.

28. Date RS, Siriwardena AK. Radiofrequency ablation of the pancreas. II: Intra-operative ablation of non-resectable pancreatic cancer. A description of technique and initial outcome. J Pancreas. 2005;6(6):588-92.

29. Liu L, Miao R, Yang H. Prognostic factors after liver resection for hepatocellular carcinoma: a single-center experience from China[J]. Am J Surg [Internet]. 2012;203.

30. Pai M, Habib N, Senturk H, Lakhtakia S, Reddy N, Cicinnati VR, et al. Endoscopic ultrasound guided radiofrequency ablation, for pancreatic cystic neoplasms and neuroendocrine tumors Clinical Trials Study. World J Gastrointest Surg [Internet]. 2015;7(4):52-9.

31. Singh V, Varshney S, Sewkani A, Varshney R, Deshpande G, Shaji P, et al. Radiofrequency ablation of unresectable pancreatic carcinoma: 10 year experience from single centre. Pancreatology. 2011;11:52.

32. Toyoda M, Kakizaki S, Horiuchi K, Katakai K, Sohara N, Sato K, et al. Computed tomography-guided transpulmonary radiofrequency ablation for hepatocellular carcinoma located in hepatic dome. World J Gastroenterol. 2006;12(4):608-11.

33. Kato $\mathrm{T}$, Yamagami $\mathrm{T}$, Hirota $\mathrm{T}$, Matsumoto $\mathrm{T}$, Yoshimatsu R, Nishimura $\mathrm{T}$. Transpulmonary radiofrequency ablation for hepatocellular carcinoma under real-time computed tomography-fluoroscopic guidance. Hepatogastroenterology. 2008;55(85):1450-3.

34. Rhim H, Lim HK, Kim YS, Choi D, Lee WJ. Radiofrequency ablation of hepatic tumors: Lessons learned from 3000 procedures. Vol. 23, Journal of Gastroenterology and Hepatology (Australia). 2008; 23: 1492-500.

35. Dromi SA, Walsh MP, Herby S, Traughber B, Xie J, Sharma K V, et al. Radiofrequency ablation induces antigen-presenting cell infiltration and amplification of weak tumor-induced immunity. Radiology [Internet]. 2009;251(1):58-66. 
36. Den Brok MHMGM, Sutmuller RPM, Van Der Voort R, Bennink EJ, Figdor CG, Ruers TJM, et al. In situ tumor ablation creates an antigen source for the generation of antitumor immunity. Cancer Res. 2004;64(11):4024-9.

37. Gameiro SR, Higgins JP, Dreher MR, Woods DL, Reddy G, Wood BJ, et al. Combination Therapy with Local Radiofrequency Ablation and Systemic Vaccine Enhances Antitumor Immunity and Mediates Local and Distal Tumor Regression. PLoS One. 2013;8(7).

38. Nierkens S, den Brok M, Ruers TJ, Adema GJ. Radiofrequency Ablation in Cancer Therapy: Tuning in to in situ Tumor Vaccines. Ultrasound Clin [Internet]. 2013;8(2):171-83.

39. Haen SP, Pereira PL, Salih HR, Rammensee HG, Gouttefangeas C. More than just tumor destruction: Immunomodulation by thermal ablation of cancer. Vol. 2011, Clinical and Developmental Immunology. 2011.

40. Widenmeyer M, Shebzukhov Y, Haen SP, Schmidt D, Clasen S, Boss A, et al. Analysis of tumor antigen-specific $\mathrm{T}$ cells and antibodies in cancer patients treated with radiofrequency ablation. Int J Cancer. 2011;128(11):2653-62.

41. Waitz R, Solomon SB. Can local radiofrequency ablation of tumors generate systemic immunity against metastatic disease? Radiology. 2009;251(1):1-2.

42. Saito K, Araki K, Reddy N, Guang W, O'Malley BW, Li D. Enhanced local dendritic cell activity and tumor-specific immunoresponse in combined radiofrequency ablation and interleukin-2 for the treatment of human head and neck cancer in a murine orthotopic model. Head Neck. 2011;33(3):359-67.

43. Zerbini A, Pilli M, Penna A, Pelosi G, Schianchi C, Molinari A, et al. Radiofrequency thermal ablation of hepatocellular carcinoma liver nodules can activate and enhance tumor-specific T-cell responses. Cancer Res. 2006;66(2):1139-46

44. Mizukoshi E, Yamashita T, Arai K, Sunagozaka H, Ueda T, Arihara F, et al. Enhancement of tumor-associated antigen-specific $\mathrm{T}$ cell responses by radiofrequency ablation of hepatocellular carcinoma. Hepatology [Internet]. 2013;57(4):1448-57.

45. Gores GJ. Early detection and treatment of cholangiocarcinoma. Liver Transpl [Internet]. 2000;6(6 Suppl 2):S30-4

46. Boberg KM, Schrumpf E. Diagnosis and Treatment of Cholangiocarcinoma. Oncologist. 2004;9(1):43-57.

47. Blechacz B, Komuta M, Roskams T, Gores GJ. Clinical diagnosis and staging of cholangiocarcinoma. Nat Rev Gastroenterol Hepatol [Internet]. 2011;8(9):512-22.

48. Kahaleh M, Tokar J, Conaway MR, Brock A, Le T, Adams RB, et al. Efficacy and complications of covered Wallstents in malignant distal biliary obstruction. Gastrointest Endosc. United States; 2005 Apr;61(4):528-33.

49. Hammarström LE. Role of palliative endoscopic drainage in patients with malignant biliary obstruction. Vol. 22, Digestive Surgery. 2005. p. 295-304.

50. Khan MA, Khan S, Khan AR, Kamal S, Khan MI, Alastal Y, et al. Endoscopic ultrasound guided biliary drainage comes of age: A systematic review and meta-analysis. Gastrointest Endosc. 2015; 5:AB421.

51. Loew BJ, Howell DA, Sanders MK, Desilets DJ, Kortan PP, May GR, et al. Comparative performance of uncoated, self-expanding metal biliary stents of different designs in 2 diameters: final results of an international multicenter, randomized, controlled trial. Gastrointest Endosc. United States; 2009 Sep;70(3):445-53.

52. Kullman E, Frozanpor F, Sderlund C, Linder S, Sandstrm P, Lindhoff-Larsson $A$, et al. Covered versus uncovered self-expandable nitinol stents in the palliative treatment of malignant distal biliary obstruction: Results from a randomized, multicenter study. Gastrointest Endosc. 2010;72(5):915-23.

53. Telford JJ, Carr-Locke DL, Baron TH, Poneros JM, Bounds BC, Kelsey PB, et al. A randomized trial comparing uncovered and partially covered self-expandable metal stents in the palliation of distal malignant biliary obstruction. Gastrointest Endosc. 2010;72(5):907-14.

54. Curley SA, Izzo F, Delrio P, Ellis LM, Granchi $\mathrm{J}$, Vallone $\mathrm{P}$, et al. Radiofrequency ablation of unresectable primary and metastatic hepatic malignancies: results in 123 patients. Ann Surg [Internet]. 1999;230(1):1-8.

55. Curley SA, Izzo F. Radiofrequency ablation of primary and metastatic hepatic malignancies. Int J Clin Oncol [Internet]. 2002;7(2):72-81.

56. Curley $\mathrm{S}$ a. Radiofrequency ablation of malignant liver tumors. Ann Surg Oncol. 2003;10(4):338-47.

57. Ng KK, Vauthey J-N, Pawlik TM, Lauwers GY, Regimbeau J-M, Belghiti J, et al. Is hepatic resection for large or multinodular hepatocellular carcinoma justified? Results from a multi-institutional database. Ann Surg Oncol. 2005;12(5):364-73.

58. Vavra P, Dostalik J, Zacharoulis D, Khorsandi SE, Khan SA, Habib NA. Endoscopic radiofrequency ablation in colorectal cancer: initial clinical results of a new bipolar radiofrequency ablation device. Dis Colon Rectum. United States; 2009 Feb;52(2):355-8.

59. Shaheen NJ, Sharma P, Overholt BF, Wolfsen HC, Sampliner RE, Wang KK, et al. Radiofrequency Ablation in Barrett's Esophagus with Dysplasia. N Engl J Med [Internet]. 2009;360(22):2277-88.

60. Orman ES, Li N, Shaheen NJ. Efficacy and durability of radiofrequency ablation for barrett's esophagus: Systematic review and meta-analysis. Vol. 11, Clinical Gastroenterology and Hepatology. 2013. p. 1245-55.

61. Hu B, Gao DJ, Wu J, Wang TT, Yang XM, Ye X. Intraductal radiofrequency ablation for refractory benign biliary stricture: Pilot feasibility study. Dig Endosc. 2014;26(4):581-5.

62. Isayama H, Nakai Y, Kawakubo K, Kogure H, Hamada T, Togawa O, et al. Endoscopic Retrograde Cholangiopancreatography for Distal Malignant
Biliary Stricture. Vol. 22, Gastrointestinal Endoscopy Clinics of North America. 2012. p. 479-90

63. Rustagi T, Jamidar PA. Intraductal Radiofrequency Ablation for Management of Malignant Biliary Obstruction. Vol. 59, Digestive Diseases and Sciences. 2014. p. 2635-41.

64. Widmer J, Sharaiha RZ, Kahaleh M. Endoscopic Ultrasonography-Guided Drainage of the Pancreatic Duct. Vol. 23, Gastrointestinal Endoscopy Clinics of North America. 2013. p. 847-61.

65. Pai M, Valek V, Tomas A, Doros A, Quaretti P, Golfieri R, et al. Percutaneous intraductal radiofrequency ablation for clearance of occluded metal stent in malignant biliary obstruction: feasibility and early results. Cardiovasc Intervent Radiol. United States; 2014 Feb;37(1):235-40.

66. Sharaiha RZ, Natov N, Glockenberg KS, Widmer J, Gaidhane M, Kahaleh M. Comparison of metal stenting with radiofrequency ablation versus stenting alone for treating malignant biliary strictures: is there an added benefit? Dig Dis Sci. United States; 2014 Dec;59(12):3099-102.

67. Hadjicostas P, Malakounides N, Varianos C, Kitiris E, Lerni F, Symeonides P. Radiofrequency ablation in pancreatic cancer. HPB (Oxford). 2006;8:61-4.

68. Varshney S, Sewkani A, Sharma S, Kapoor S, Naik S, Sharma A, et al. Radiofrequency ablation of unresectable pancreatic carcinoma: feasibility, efficacy and safety. JOP. 2006;7(1):74-8.

69. Spiliotis JD, Datsis AC, Michalopoulos N V., Kekelos SP, Vaxevanidou A, Rogdakis AG, et al. Radiofrequency ablation combined with palliative surgery may prolong survival of patients with advanced cancer of the pancreas. Langenbeck's Archives of Surgery. 2007; 392:55-60.

70. Girelli R, Frigerio I, Salvia R, Barbi E, Tinazzi Martini P, Bassi C. Feasibility and safety of radiofrequency ablation for locally advanced pancreatic cancer. Br J Surg. 2010;97(2):220-5.

71. Wu Y, Tang Z, Fang H, Gao S, Chen J, Wang Y, et al. High operative risk of cool-tip radiofrequency ablation for unresectable pancreatic head cancer 1 . J Surg Oncol. 2006;94(5):392-5.

72. Zou YP, Li WM, Zheng F, Li FC, Huang H, Du JD, et al. Intraoperative radiofrequency ablation combined with 125 iodine seed implantation for unresectable pancreatic cancer. World J Gastroenterol. 2010;16(40):5104-10.

73. Siriwardena AK. Radiofrequency ablation for locally advanced cancer of the pancreas. JOP : Journal of the pancreas. Italy; 2006;7:1-4 